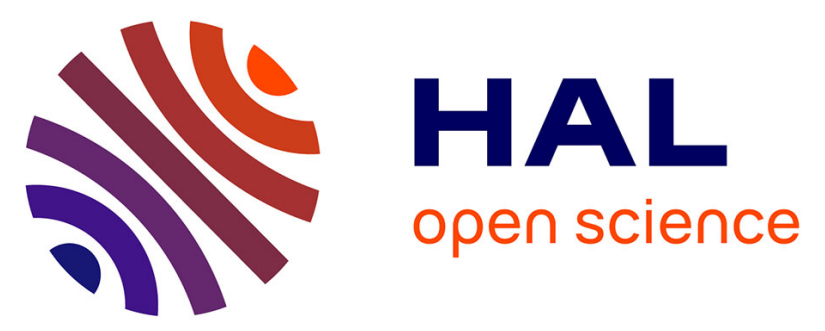

\title{
1H NMR and computational study of the conformations in solution of one host/guest complex formed with an usnic acid tweezer and 2,4,7-trinitro-9-fluorenone (TNF)
}

Eric Hitti, Béatrice Legouin, Jérôme Graton, Denis Jacquemin, Philippe Uriac

\section{- To cite this version:}

Eric Hitti, Béatrice Legouin, Jérôme Graton, Denis Jacquemin, Philippe Uriac. 1H NMR and computational study of the conformations in solution of one host/guest complex formed with an usnic acid tweezer and 2,4,7-trinitro-9-fluorenone (TNF). Tetrahedron, 2016, 72 (22), pp.2890-2894. 10.1016/j.tet.2016.03.100 . hal-01298758

\section{HAL Id: hal-01298758}

https://hal-univ-rennes1.archives-ouvertes.fr/hal-01298758

Submitted on 2 Sep 2016

HAL is a multi-disciplinary open access archive for the deposit and dissemination of scientific research documents, whether they are published or not. The documents may come from teaching and research institutions in France or abroad, or from public or private research centers.
L'archive ouverte pluridisciplinaire HAL, est destinée au dépôt et à la diffusion de documents scientifiques de niveau recherche, publiés ou non, émanant des établissements d'enseignement et de recherche français ou étrangers, des laboratoires publics ou privés. 


\section{Graphical Abstract}

1H NMR and computational study of the conformations

in solution of one host/guest complex formed with an

usnic acid tweezer and 2,4,7-trinitro-9-fluorenone (TNF)

Eric Hitti, ${ }^{\mathrm{a}, \mathrm{b}}$ Béatrice Legouin, ${ }^{\mathrm{c}}$ Jérôme Graton, ${ }^{\mathrm{d}}$

Denis Jacquemin ${ }^{\mathrm{d}, \mathrm{e}}$ and Philippe Uriac ${ }^{\mathrm{c}^{*}}$

${ }^{a}$ Université de Rennes 1, LTSI, Rennes, F-35000, France

${ }^{b}$ INSERM, U1099, Rennes, F-35000, France

${ }^{c}$ PNSCM - UMR CNRS 6226-Université de Rennes 1, Université Bretagne Loire, 2 Avenue du Pr. Leon Bernard, Rennes 35043- France

${ }^{d}$ Chimie et Interdisciplinarité: Synthèse, Analyse, Modélisation (CEISAM), UMR CNRS 6230, Université de Nantes, 2 rue de la Houssinière, Nantes 44322, France

${ }^{e}$ Institut Universitaire de France, 1 rue Descartes, Paris 75231, France.

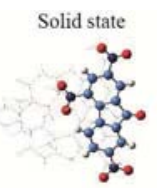

X-ray structure

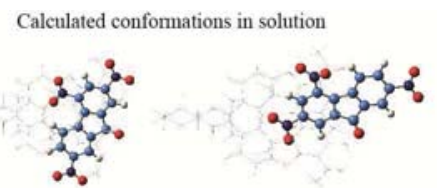

«Longitudinal» $51 \%$
"Lateral»

$49 \%$ 


\title{
1H NMR and computational studies of the conformations in solution of one host/guest complex formed with an usnic acid tweezer and 2,4,7-trinitro-9- fluorenone (TNF)
}

\author{
Eric Hitti ${ }^{\mathrm{a}, \mathrm{b}}$, Béatrice Legouin ${ }^{\mathrm{c}}$, Jérôme Graton ${ }^{\mathrm{d}}$, Denis Jacquemin ${ }^{\mathrm{d}, \mathrm{e}}$ and Philippe Uriac ${ }^{\mathrm{c}}$ * \\ ${ }^{a}$ Université de Rennes 1, LTSI, Rennes, F-35000, France, \\ ${ }^{b}$ INSERM, U1099, Rennes, F-35000, France \\ c PNSCM - UMR CNRS 6226-Université de Rennes 1, Université Bretagne Loire, 2 Avenue du Pr. Leon Bernard, Rennes 35043- France \\ ${ }^{d}$ Chimie et Interdisciplinarité: Synthèse, Analyse, Modélisation (CEISAM), UMR CNRS 6230, Université de Nantes, 2 rue de la Houssinière, Nantes 44322, \\ France \\ ${ }^{e}$ Institut Universitaire de France, 1 rue Descartes, Paris 75231, France.
}

\begin{abstract}
In a host-guest model formed by a molecular tweezer 4, bearing two usnic acid units, and TNF, the TNF protons chemical shifts are measured at various temperatures. With the help of a computational study, the geometries of complexation of this host-guest system are identified and their TNF protons chemical shifts calculated. Data analysis led to conclude that in solution two types of conformations are present: the "lateral" one (similar to the structure found in the solid state) and the "longitudinal" one in which the TNF is less engaged inside the host. The proportion of the latter increases with decreasing temperatures.
\end{abstract}

* Corresponding author. Tel.: +33 2232347 90; e-mail: philippe.uriac@univ-rennes1.fr 
In both solution or solid state, supramolecular organizations based on weak interactions such as $\pi-\pi$ stacking or $\mathrm{C}-\mathrm{H} / \pi$ interactions lead to molecular structures of interest in various fields, e.g., catalysis, medicinal and material chemistry. In the framework of a better understanding of molecular self assembly and molecular recognition, numerous tweezers have been synthesized. ${ }^{1-4}$ Whilst the position of various guests in tweezers has been unambiguously determined in the solid state by X-ray diffraction, conformational studies of host/guest complexes in solution are, to the very best of our knowledge much less common. Y. Fukazawa et al. ${ }^{5}$ have determined some structures of one complex between a flexible tweezer 1 and the pyromellitic dianhydride by comparing experimental and simulated ${ }^{1} \mathrm{H}$ NMR chemical shifts. An extensive conformational study has also been performed by Klärner et al in both solution ${ }^{6}$ and solid state. ${ }^{7}$ A rotation of the hosts inside the "clips" cavity 2 was observed using ${ }^{1} \mathrm{H}$ NMR in solution (with tetracyanobenzene) or in solid state (dicyanobenzene). More recently, Y. Tsuchido et al. ${ }^{8}$ have used ROESY measurements to investigate the position of a TNF derivative inside their tweezer 3 (Fig. 1). In all these systems, either the size of the cavity is large enough to allow the rotation or flip of the guest inside the cavity or the tweezer backbone is sufficiently flexible to accommodate several kinds of interactions.
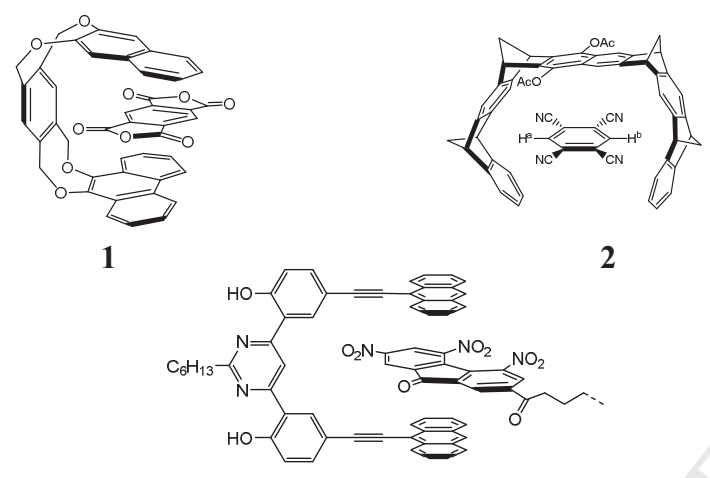

2 different temperatures with various $[4] /[\mathbf{T N F}]$ ratio $(r)$ as well as the structures of the possible conformations revealed by a firstprinciple study. The comparison of experimental and theoretical ${ }^{1} \mathrm{H}$ NMR results, performed using the NNLS (Non-Negativityconstrained Least Squares) technique of Lawson and Hanson, ${ }^{11}$ allowed us to unravel the most favored conformations.

\section{Results and discussion}

\subsection{NMR measurements}

The complex formation led to upfield shifts $\Delta \delta_{\mathrm{H}}$ when it was followed by ${ }^{1} \mathrm{H}$ NMR. The titrations were carried out at different temperatures $(232-253-278-288-298 \mathrm{~K})$ in $\mathrm{CD}_{2} \mathrm{Cl}_{2}$. The complexation-induced NMR shifts $\Delta \delta$ of each of the guest protons were determined by calculation of the variation $\Delta \delta_{\mathrm{H}}=$ $\delta_{\mathrm{H}}\left(\mathbf{T N F}\right.$ in $\left.\mathrm{CD}_{2} \mathrm{Cl}_{2}\right)-\delta_{\mathrm{H}}(\mathbf{T N F}$ in titration solution) for the ratio $r=[4] /[\mathbf{T N F}]$ (Fig. 2). The diagrams $\Delta \delta_{\mathrm{H}} v s r$ at each temperature showed a speciific evolution for each proton attesting the "mapping" of the interactions (See the Supplementary data). As illustrated in Table 1 for the experiment carried out at $298 \mathrm{~K}, \mathrm{H} 1$ and $\mathrm{H} 8$ of TNF, close to the carbonyl function, are more shielded than the other protons. Indeed $\Delta \delta_{\mathrm{H}}$ is ca. $0.2 \mathrm{ppm}$ for $\mathrm{H} 3, \mathrm{H} 5$ and $\mathrm{H} 6$ but attains ca. $0.4 \mathrm{ppm}$ for $\mathrm{H} 1$ and $\mathrm{H} 8$ for $r=36.8$. At lower temperatures, a similar behavior of the studied system is observed (experimental values are reported in the supplementary data). The evaluation of the association constant $\mathrm{K}$ encompassing the $232-298 \mathrm{~K}$ temperature range can give access to the enthalpy $\Delta H$ and entropy $\Delta S$ of association ${ }^{6,12}$. The variable-temperature data were fit to the linear van't Hoff equation leading to temperature-invariant thermodynamic values that demonstrated the large influence of an enthalpic interaction in the complex formation as expected in the molecular recognition $(\Delta \mathrm{G}=-2.3$ kcal.mol ${ }^{-1}(298 \mathrm{~K}), \Delta \mathrm{H}=-2.9 \mathrm{kcal} . \mathrm{mol}^{-1}$ and $\Delta \mathrm{S}=-1.9 \mathrm{cal} . \mathrm{mol}^{-}$ ${ }^{1} \cdot \mathrm{K}^{-1}$ ) (see the supplementary data)

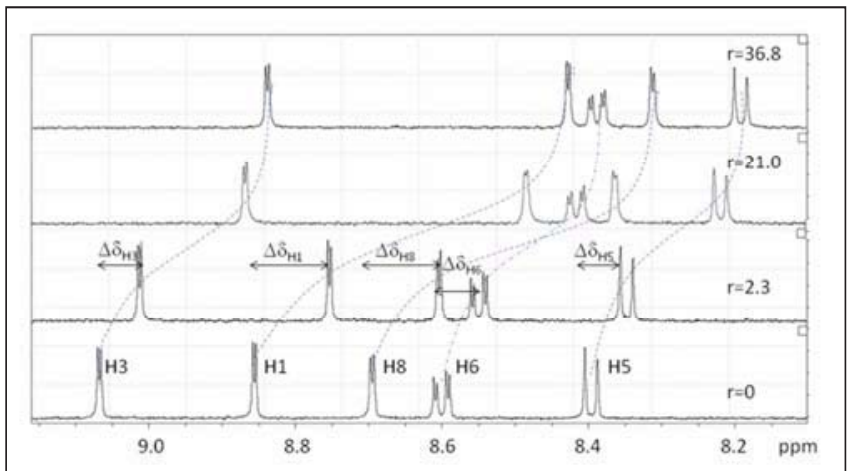

Fig. 2: Partial NMR spectra of TNF @ 4 in $\mathrm{CH}_{2} \mathrm{Cl}_{2}$ at $298 \mathrm{~K}$ at different ratio $r,[\mathrm{TNF}]=1.99 \mathrm{mM}$ being constant.

Table $1: \Delta \delta$ in ppm of the TNF protons at different $r$ at $298 \mathrm{~K}$ and $\Delta \delta \max$ (calculated)

$\mathrm{ppm}$ ) the shift of which is very far from the TNF ones. Indeed, thorough "mapping" of the interaction with TNF can therefore be expected thanks to its five aromatic protons, all of them being differently surrounded.

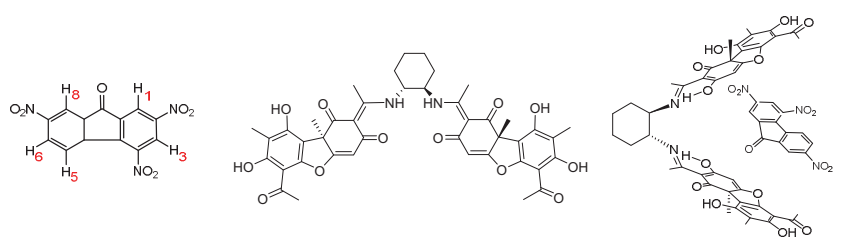

\begin{tabular}{cccccccc}
\hline & $\mathrm{r}=1.2$ & $\mathrm{r}=5.2$ & $\mathrm{r}=12.3$ & $\mathrm{r}=21$ & $\mathrm{r}=33.3$ & $\mathrm{r}=36.8$ & $\Delta \delta \max$ \\
\hline H1 & 0.056 & 0.188 & 0.298 & 0.370 & 0.422 & 0.428 & 0.544 \\
H3 & 0.030 & 0.102 & 0.160 & 0.199 & 0.226 & 0.230 & 0.290 \\
H5 & 0.027 & 0.089 & 0.142 & 0.176 & 0.201 & 0.204 & 0.260 \\
H6 & 0.028 & 0.093 & 0.147 & 0.183 & 0.209 & 0.212 & 0.270 \\
H8 & 0.050 & 0.168 & 0.266 & 0.331 & 0.377 & 0.382 & 0.486 \\
\hline
\end{tabular}


2.2. Computational study ACCEPTED MA Fig. 3 with a constant orientation of the host molecule, are

The structures of $\mathbf{4}, \mathbf{T N F}$ and their complexes $\mathbf{C}_{\mathbf{i}}$ were investigated using a DFT-D model that account for dispersion interactions (see Experimental section). Starting from the available XRD structure ${ }^{10}$, the potential energy surface (PES) of TNF@4 has been thoroughly investigated through the rotation and translation of the TNF moiety inside the tweezer molecule. The proton magnetic shielding constants were next determined on each optimal structure. These calculations allowed the determination of the theoretical $\Delta \delta_{\mathrm{H}}$ values for each proton of each conformation considering both the free TNF and bound TNF (Table 2).

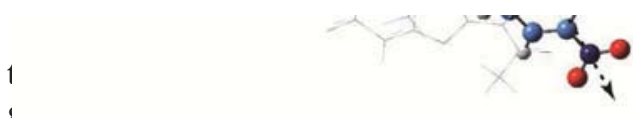

Selected tweezer orientation

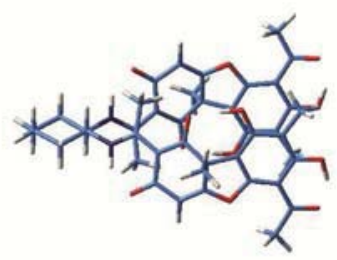
characterized by the different orientations of the TNF inside 4 . At first, the orientation of the TNF (symbolized by the arrow connecting the two nitro groups in positions 2 and 7) can be divided into two groups, with either a lateral introduction of TNF in $\mathbf{4}$ in the conformations $\mathbf{C}_{\mathbf{1 - 5}}$, similarly to what is found in the solid state $\left(\mathbf{C}_{\text {ref }}\right),{ }^{10}$ or a longitudinal introduction in the $\mathbf{C}_{6-7}$ conformations. For the lateral conformations, a second feature is the position of the carbonyl group that can be found at the periphery of the complex $\left(\mathbf{C}_{\mathbf{1 , 2 , 4 , 5}}\right)$ or closer to its center $\left(\mathbf{C}_{\mathbf{3}}\right)$. It should be noted that, owing to the symmetry of both the TNF and 4 structures, all these conformations have their equivalent through a rotation of $180^{\circ}$ of the TNF structure around the $C_{2}$ axis of 4, as illustrated in Fig. 4, with the example of conformation $\mathrm{C}_{1}$ and its equivalent $\mathrm{C}_{-1}$.

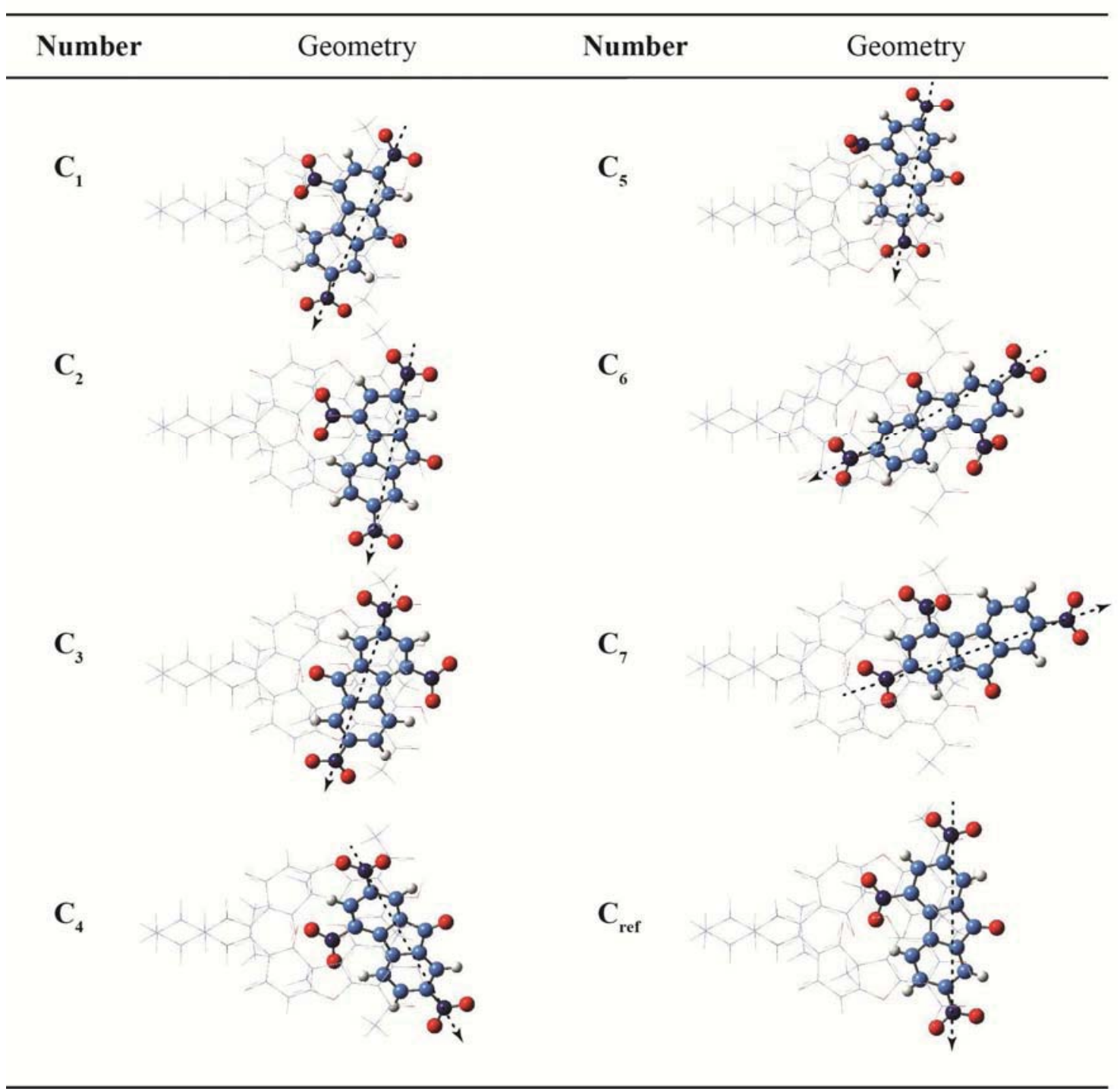


Fig. 3 : Geometries of the complex TNF@4 resulting from the conformational study. At the top, one can see the constant tweezer orientation.

Table 2 : Theoretical $\Delta \delta(\delta$ (complexed $)-\delta$ (free $))$ of the TNF protons depending on the given conformations

\begin{tabular}{lccccccc}
\hline & $\mathbf{C}_{\mathbf{1}}$ & $\mathbf{C}_{\mathbf{2}}$ & $\mathbf{C}_{\mathbf{3}}$ & $\mathbf{C}_{\mathbf{4}}$ & $\mathbf{C}_{\mathbf{5}}$ & $\mathbf{C}_{\mathbf{6}}$ & $\mathbf{C}_{\mathbf{7}}$ \\
\hline H1 & 0.449 & 0.201 & 0.580 & 0.502 & 0.030 & 0.283 & 1.579 \\
$\mathbf{H 3}$ & -0.219 & 0.213 & 0.143 & 0.157 & 0.076 & 0.115 & 0.679 \\
$\mathbf{H 5}$ & -0.072 & -0.303 & -0.311 & -0.482 & 0.856 & 0.384 & 0.090 \\
H6 & 0.187 & -0.113 & 0.085 & -0.078 & 1.656 & 0.328 & -0.009 \\
H8 & 0.304 & 0.150 & 0.161 & -0.050 & 0.782 & 1.542 & 0.034 \\
\hline
\end{tabular}

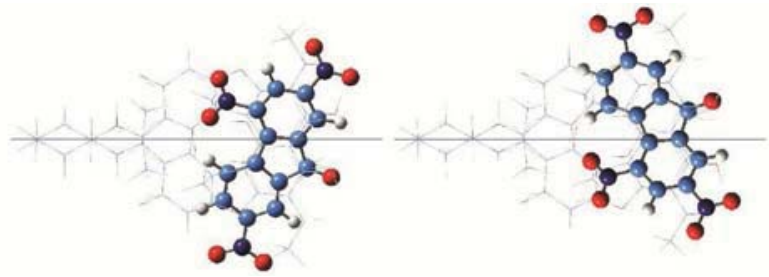

Fig. 4: Equivalent geometries encountered upon rotation of the TNF guest around the $C_{2}$ axis (shown) of the host 4 .

\subsection{Correlation study}

To determine the proportion of each conformer, for a given temperature (T) and ratio $r$, the experimental and theoretical $\Delta \delta_{\mathrm{H}}$ values were compared. For a given proton, each real chemical shift $\Delta \delta_{\mathrm{H}}$ is a linear combination of its theoretical chemical shift $\Delta \delta_{\mathrm{H}-\mathrm{Ci}}$ for each conformer depending on its presence in the mixture. $\Delta \delta_{\mathrm{H}}$ value is obtained from the NMR measurements (Table 1) whereas the $\Delta \delta_{\mathrm{H}-\mathrm{Ci}}$ are theoretically obtained (Table 2 )

$$
\begin{aligned}
& \Delta \delta_{H_{j}}=\sum_{i=1}^{n} p_{i} \Delta \delta_{H_{j}\left(C_{i}\right)} \text { for a given } \mathrm{H} \\
& \text { with } \sum_{i=1}^{n} p_{i}=1 \text { and } p_{0} \text { the free } \mathbf{T N F} \text { proportion (see } \\
& \text { supplementary data) }
\end{aligned}
$$

Once the $p_{0}$ is calculated the $p_{\text {i }}$ proportions are calculated by solving a system of equations under non-negative constraints of the parameters. The data analysis was performed using the NNLS technique of Lawson and Hanson. ${ }^{11}$ The Kernel of the NLLS algorithm was taken as the theoretical chemical shifts of each complex. Repeating this process for each $r$ value, we can observe the evolution of the proportion of each conformer for a given temperature (Table 3 for $\mathrm{T}=298 \mathrm{~K}$ and supplementary data for the other temperatures, the last column giving an estimate of the percentage of each conformer when $r \rightarrow \infty$ ).

At first glance, we can see that several conformers $\left(\mathbf{C}_{1}, \mathbf{C}_{3}\right.$ and $\mathbf{C}_{4}$ ) are actually found in insignificant proportions in $\mathrm{CD}_{2} \mathrm{Cl}_{2}$. At $298 \mathrm{~K}$, the proportion of TNF@4 complex increases from $11 \%$ to $81 \%$ with the increase of concentration of 4 (Table 3). Among the associated systems, the relative populations $\left(\mathbf{C}_{\mathbf{i}} \% /(100 \%\right.$ -
TNF\%)) of the four other conformers $\left[\mathbf{C}_{2}(33 \%), \mathbf{C}_{5}(18 \%), \mathbf{C}_{6}\right.$ $(21 \%)$ and $\left.\mathbf{C}_{7}(28 \%)\right]$ are predicted by our model to be independent of $r$ within an uncertainty of ca. $4 \%$. Moreover, with the decrease of temperature (see the supplementary data), the whole complex population is roughly increasing, but the individual populations of the various conformers are still computed to be constant with increasing concentration ratio. This illustrates the robustness of the established model since at a given temperature the proportion of the various conformers of TNF@4 is expected to be constant irrespective of the concentration ratio. Moreover, as reported in both Table 4 and Fig.5, the two longitudinal conformers $\mathbf{C}_{6}$ and $\mathbf{C}_{7}$ are favored at lower temperature, reaching $64 \%$ at $232 \mathrm{~K}$. On the contrary, when considered together, the two lateral conformers $\mathbf{C}_{2}$ and $\mathbf{C}_{5}$ dominate the blend at higher temperature. These are much more similar to the crystalline structure, grown at room temperature. ${ }^{10}$

Table 3: Proportion in percentage (\%) of each conformer and the free $\mathbf{T N F}$ for $\mathrm{T}=298 \mathrm{~K}$

\begin{tabular}{cccccccc}
\hline & \multicolumn{9}{c}{$r$} & \multicolumn{4}{c}{$\begin{array}{c}\text { Relative } \\
\text { conformer (\%) }\end{array}$} \\
\hline & 1.2 & 5.2 & 12.3 & 21.0 & 33.3 & 36.8 & \\
\hline $\mathbf{C}_{\mathbf{1}}$ & 0 & 0 & 0 & 0 & 0 & 0 & 0 \\
$\mathbf{C}_{\mathbf{2}}$ & 3 & 11 & 18 & 22 & 25 & 26 & 33 \\
$\mathbf{C}_{\mathbf{3}}$ & 0 & 0 & 0 & 0 & 0 & 0 & 0 \\
$\mathbf{C}_{\mathbf{4}}$ & 0 & 0 & 0 & 0 & 0 & 0 & 0 \\
$\mathbf{C}_{\mathbf{5}}$ & 2 & 6 & 10 & 12 & 14 & 14 & 18 \\
$\mathbf{C}_{\mathbf{6}}$ & 2 & 7 & 11 & 14 & 16 & 16 & 21 \\
$\mathbf{C}_{\mathbf{7}}$ & 3 & 10 & 15 & 19 & 21 & 22 & 28 \\
$\mathbf{T N F} \mathbf{4}$ & 11 & 35 & 56 & 70 & 78 & 81 & \\
$\mathbf{T N F}$ & 89 & 65 & 44 & 30 & 22 & 19 & \\
\hline
\end{tabular}

Table 4: Relative percentage of each conformers $\left(C_{i}\right)$ at different temperatures

\begin{tabular}{cccccc}
\hline & $232 \mathrm{~K}$ & $253 \mathrm{~K}$ & $278 \mathrm{~K}$ & $288 \mathrm{~K}$ & $298 \mathrm{~K}$ \\
\hline $\mathbf{C}_{\mathbf{1}}$ & 0 & 0 & 0 & 0 & 0 \\
$\mathbf{C}_{\mathbf{2}}$ & 22 & 21 & 26 & 27 & 33 \\
$\mathbf{C}_{\mathbf{3}}$ & 0 & 0 & 0 & 0 & 0 \\
$\mathbf{C}_{\mathbf{4}}$ & 0 & 0 & 0 & 0 & 0 \\
$\mathbf{C}_{\mathbf{5}}$ & 14 & 16 & 17 & 18 & 18 \\
$\mathbf{C}_{\mathbf{6}}$ & 30 & 29 & 25 & 24 & 21
\end{tabular}




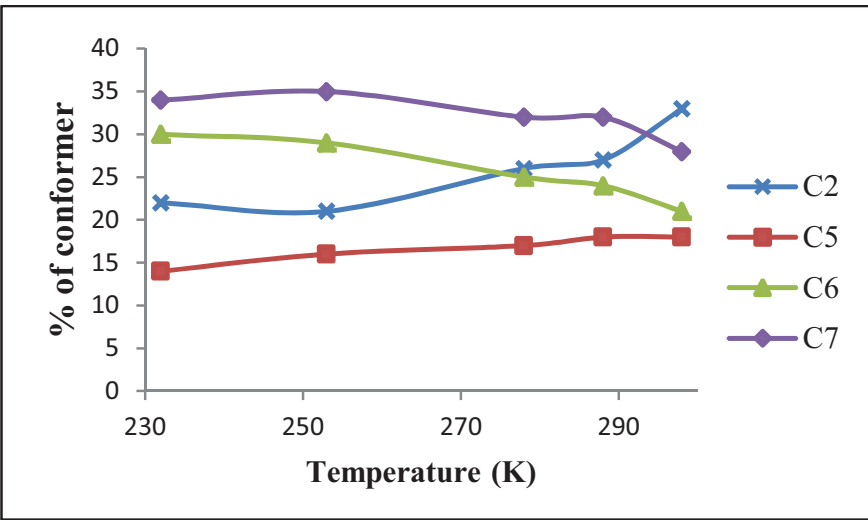

Fig. 5: Relative proportion of each conformer depending on temperature

Fig. 3) it can be noticed that the $\mathbf{C}_{\mathbf{2}} / \mathbf{C}_{\mathbf{5}}$ equilibrium is possible by a simple translation of the $\mathbf{T N F}$, accompanied by an internal rotation of a nitro group. Because of the steric hindrance between 4 and $\mathbf{T N F}$, the $\mathbf{C}_{6} / \mathbf{C}_{7}$ equilibrium which could theoretically occur by a $180^{\circ} \mathrm{flip}$, is clearly much less probable. Finally, the conversion of the "lateral" conformations $\mathbf{C}_{2}$ and $\mathbf{C}_{5}$ into the "longitudinal" ones $\mathbf{C}_{6}$ and $\mathbf{C}_{7}$ needs the $\mathbf{T N F}$ release. Thus, the equilibrium between the four major conformers observed in solution should result principally from a mutual dissociationassociation of the TNF@4. One can note that Klärner et al. with a guest presenting a large cavity and a small molecule as a host, has demonstrated that a rotation of the host inside the guest can also occur both in solution and in solid phase. ${ }^{6,7}$

\section{Conclusion}

The study of the conformations of TNF@4 in solution, a guest@host model with low association constant, has allowed us confirming that the conformations found in the solid state and in solution significantly differ particularly at low temperatures. Another important result of this work is that it provides a solid argumentation to propose that the mutual dissociation-association is the major phenomenon that determines the conformational equilibrium of our specific TNF@4 exhibiting the dynamic process of the molecular recognition in solution. Obviously, comparisons between the theoretically calculated Gibbs energies of complexation and the population of complexes fitted from NMR data would be of great interest. Nevertheless, an accurate estimation of complexation Gibbs energies requires much more sophisticated theoretical calculations, with much larger basis set, taking into account solvent effects, anharmonic contributions, dispersion effects...

\section{Experimental section}

\subsection{General}

NMR spectra were recorded on a Bruker DMX 500 WB NMR spectrometer in $\mathrm{CD}_{2} \mathrm{Cl}_{2}$. The undeuterated residue of the solvent was used as internal standard. The data analysis was performed using Matlab (Matlab R2008, MathWorks, Natick, MA).
${ }^{1} \mathrm{H}$ NMR experimental data were obtained from titrations carried out at different temperatures $(232-253-278-288-$ $298 \mathrm{~K}$ ) in $\mathrm{CD}_{2} \mathrm{Cl}_{2}$. Aliquots of a stock solution of 4 at $0.080 \mathrm{M}$ in a solution of TNF led to titrations solutions encompassing a range of 0 to 40 for the ratio $r=[4] /[\mathbf{T N F}]$. The complexationinduced NMR shifts $\Delta \delta$ of each of the guest proton were determined by calculation of the variation $\Delta \delta_{\mathrm{H}}=\delta_{\mathrm{H}}$ (TNF in $\left.\mathrm{CD}_{2} \mathrm{Cl}_{2}\right)-\delta_{\mathrm{H}}(\mathrm{TNF}$ in titration solution)

\subsection{DFT calculations}

All calculations were performed using the Gaussian 09 program. ${ }^{13}$ According to a previous work $^{14}$, the B97-D ${ }^{15}$ functional and the 6-31G(d) basis set have been employed to optimize all geometries. We started from the available XRD structure, ${ }^{10}$ and considered many relative orientations of the host and the guest. The harmonic frequencies were computed analytically at the same level of theory in order to characterize the stationary points. The proton magnetic shielding constants were computed via GIAO method including the dichloromethane solvent effects through single-point Polarizable Continuum Model (PCM) calculations ${ }^{16}$ at the PBE0/cc-pVTZ level of theory. Absolute isotropic shielding constants were also calculated for the reference material, TMS, and the values of proton chemical shifts were obtained as the difference between the proton shielding constants for the investigated complexes and that for TMS (see the supplementary data).

\section{Supplementary data}

Supplementary data associated with this article can be found in the online version, at http://dx.doi.org/

\section{Acknowledgments}

The authors are also grateful like to A. Bondon for fruitful discussion.

\section{References and notes}

1. Hardouin-Lerouge, M.; Hudhomme, P.; Sallé, M. Chem.Soc. Rev. 2011, 40, 30-43.

2. Harmata, M. Acc. Chem. Res. 2004, 37, 862-873.

3. Leblond, J.; Petitjean, A. ChemPhysChem 2011, 12, 1043-1051.

4. Chou, T.-C.; Li, Y.-J. Tetrahedron 2015, 71, 56205633.

5. Kurebayashi, H.; Haino, T.; Usui, S.; Fukazawa, Y. Tetrahedron 2001, 8667-8674.

6. Klärner, F.-G.; Kahlert, B. Acc. Chem. Res. 2003, 36, 919-932.

7. Brown, S. P.; Schaller, T.; Seelbach, U. P.; Koziol, F.; Ochsenfeld, C.; Klärner, F.-G.; Spiess, H. W. Angew. Chem. Int. Ed. 2001, 40, 717-720. 
Tsuchido, Y.; Suzaki, Y.; Ide, T.; Osakada, K.PTED MANU Bearpark, M.; Heyd, J. J.; Brothers, E.; Kudin, K. N.; Chemistry 2014, 20, 4762-71.

9. $\quad$ Legouin, B.; Gayral, M.; Uriac, P.; Cupif, J. F.; Levoin, N.; Toupet, L.; Van De Weghe, P. European J. Org. Chem. 2010, 5503-5508.

10. Legouin, B.; Uriac, P.; Tomasi, S.; Toupet, L.; Bondon, A.; van de Weghe, P. Org. Lett. 2009, 11, 745-748.

11. Lawson, C. L.; Hanson, R. J. Solving Least Squares Problems; 1974.

12. Stauffer, D.; Barrans, R. E. Jr.; Dougherty, D. A. J. Org. Chem. 1990, 55, 2762-2767.

13. Frisch, M. J.; Trucks, G. W.; Schlegel, H. B.; Scuseria, G. E.; Robb, M. A.; Cheeseman, J. R.; Scalmani, G.; Barone, V.; Mennucci, B.; Petersson, G. A.; Nakatsuji, H.; Caricato, M.; Li, X.; Hratchian, H. P.; Izmaylov, A. F.; Bloino, J.; Zheng, G.; Staroverov, N.; Kobayashi, R.; Normand, J.; Raghavachari, K.; Rendell, A.; Burant, J. C.; Iyengar, S. S.; Tomasi, J.; Cossi, M.; Rega, N.; Millam, J. M.; Klene, M.; Knox, J. E.; Croos, J. B.; Bakken, V.;

Adamo, C.; Jaramillo, J.; Gomperts, R.; Stratmann, R. E.; Yazyev, O.; Austin, A. J.; Cammi, R.; Pomelli, C.; Ochterski, J. W.; Martin, R. L.; Morokuma, K.; Zakrzewski, V. G.; Voth, G. A.; Salvador, P.; Dannenberg, J. J.; Dapprich, S.; Daniels, A. D.; Farkas, O.; Foresman, J. B.; Ortiz, J. V.; Cioslowski, J.; Fox, D. J. Gaussian 09; Gaussian, Inc: Wallingford : Connecticut, 2009.

14. Graton, J.; Le Questel, J.-Y.; Legouin, B.; Uriac, P.; van de Weghe, P.; Jacquemin, D. Chem. Phys. Lett. 2012, 522, 11-16.

15. Grimme, S. J. Comput. Chem. 2006, 1787-1799.

16. Tomasi, J.; Mennucci, B.; Cammi, R. Chem. Rev. 2005, 105, 2999-3093. Fukuda, R.; Hasegawa, J.; Ishida, M.; Nakajima, T.; Honda, Y.; Kitao, O.; Nakai, H.; Vreven, T.; Montgomery, J.; J.E.Peralta, J. A.; Ogliaro, F.; 